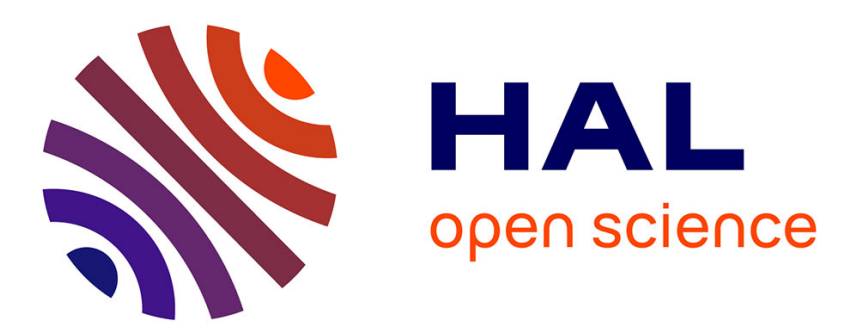

\title{
Impact of anti-hypertensive therapy in the sexual health of men and women: an analysis from the SPRINT trial
}

\author{
Joao Pedro Ferreira, Michael Böhm, Patrick Rossignol, Faiez Zannad
}

\section{To cite this version:}

Joao Pedro Ferreira, Michael Böhm, Patrick Rossignol, Faiez Zannad. Impact of anti-hypertensive therapy in the sexual health of men and women: an analysis from the SPRINT trial. American Journal of Hypertension, 2021, 10.1093/ajh/hpab035 . hal-03169827

\section{HAL Id: hal-03169827 \\ https://hal.univ-lorraine.fr/hal-03169827}

Submitted on 15 Mar 2021

HAL is a multi-disciplinary open access archive for the deposit and dissemination of scientific research documents, whether they are published or not. The documents may come from teaching and research institutions in France or abroad, or from public or private research centers.
L'archive ouverte pluridisciplinaire HAL, est destinée au dépôt et à la diffusion de documents scientifiques de niveau recherche, publiés ou non, émanant des établissements d'enseignement et de recherche français ou étrangers, des laboratoires publics ou privés. 
Impact of anti-hypertensive therapy in the sexual health of men and women: an analysis from the SPRINT trial

Authors:

João Pedro Ferreira ${ }^{1}$; Michael Böhm²; Patrick Rossignol ${ }^{1}$; Faiez Zannad ${ }^{1}$

Affiliations:

${ }^{1}$ Université de Lorraine, Centre d'Investigations Cliniques Plurithématique Inserm 1433, Nancy, France, CHRU de Nancy, Inserm U1116, Nancy, France, FCRIN INI-CRCT, Nancy, France.

${ }^{2}$ Klinik für Innere Medizin III, Saarland University Medical Center, Kirrberger Str. 1, 66421 Homburg, Germany.

Contact to:

Dr João Pedro Ferreira

Centre d'Investigation Clinique 1433 module Plurithématique

CHRU Nancy - Hopitaux de Brabois

Institut Lorrain du Coeur et des Vaisseaux Louis Mathieu

4 rue du Morvan, 54500 Vandoeuvre les Nancy

Tel : +33 (0) 383157315 
Fax : +33 (0) 383157324

Mail: j.ferreira@chru-nancy.fr 


\section{Abstract}

Background: Pharmacologic anti-hypertensive $(\mathrm{HT})$ treatment reduces cardiovascular risk. However, many patients are non-adherent due to perceived or real concern about sexualrelated side-effects.

Objectives: In a subset of the SPRINT (a randomized trial of intensive versus standard bloodpressure control) trial, we sought to investigate the impact of anti-HT treatment on sexual activities of men and women over time, and whether this impact varied with a more or less intensive anti-HT therapy.

Methods: Random-effects models for panel/longitudinal data.

Results: Among the 1268 men and 613 women included in this sub-study, 862 (68\%) men and $178(29 \%)$ women declared to be engaged in sexual activity of any kind. Compared with women and men not engaged in sexual activity, those engaged were younger (64 vs. 69yr for women and 65 vs. $75 y$ r for men). Women had an overall low satisfaction with their sexual life but their sexual health was not affected by anti-HT therapy over time nor modified by an intensive treatment. Men's erections were slightly deteriorated over time (0.1 to -0.2 points on a scale of 1 (worse) to 5 (best); $p<0.05$ ), but were not aggravated by intensive anti-HT therapy ( $p>0.05$ for all).

Conclusions: Self-declared women`s sexual health was not affected by an intensive anti-HT therapy. Men, reported a slight deterioration in the quality of their erections, irrespective of standard or intensive therapy. These findings may help reassuring patients about the sexual safety of intensive anti-HT therapy, therefore, potentially improving adherence to intensive therapy strategy. 
Key-words: sexual health; hypertension; anti-hypertensive treatment. 


\section{Condensed abstract}

In SPRINT (a randomized trial of intensive versus standard blood-pressure control), women had an overall low satisfaction with their sexual life but their sexual health was not affected by anti-hypertensive therapy over time nor modified by an intensive treatment. On the other hand, men's erections were slightly deteriorated over time, but were not furtherly aggravated by an intensive anti-hypertensive therapy. These findings have clinical implications as they may help reassuring patients about the sexual safety of intensive antihypertensive therapy, therefore, potentially improving treatment adherence. 


\section{Introduction}

Arterial hypertension (HT) affects more than $25 \%$ of the adult population worldwide regardless of sex $^{1}$. Pharmacologic treatment of HT is key to reduce the cardiovascular risk associated with uncontrolled blood pressure (BP). However, many patients are not willing to take their anti-HT drugs due to concern about side-effects ${ }^{2}$. Long-term treatment nonadherence is one of the major causes for uncontrolled BP and, consequently, increasing the morbidity and mortality risk (e.g., stroke, myocardial infarction, renal insufficiency, and death) $)^{3}$

In clinical practice, sexual side-effects are frequently evoked as an important reason for not taking the anti-HT treatment. Particularly younger, sexually active men often complain of erectile dysfunction; whereas women report less sexual side effects ${ }^{4}$. Moreover, sexual side-effects may be under-recognized, and under-reported because of difficulties in approaching the problem both by the patient and the clinician ${ }^{5}$. Hypertension itself can also cause sexual dysfunction in the long-term which might be seen by patients as a far away, unlikely future; however, the treatment side-effects occur and are felt in the present, leading to poor treatment adherence and discontinuation - a "so-called" present-self vs. future-self conflict ${ }^{6}$.

In a subset of the SPRINT (a randomized trial of intensive versus standard bloodpressure control) trial ${ }^{7}$, patients were questioned about their sexual activities at baseline and throughout the follow-up using validated sexual health questionnaires. This study sought to investigate the impact of anti-HT treatment on self-declared sexual activities over time, and whether this impact could vary with a more or less intensive anti-HT therapy in men and women. 


\section{Methods}

\section{Trial oversight}

SPRINT was sponsored by the NHLBI, with co-sponsorship by the National Institute of Diabetes and Digestive and Kidney Diseases, the National Institute of Neurological Disorders and Stroke, and the National Institute on Aging. The rationale and protocol for the trial have been previously published and are publicly available ${ }^{7,8}$. All participants provided written informed consent to participate in the study. The authors of this manuscript had authorization from the National Institutes of Health ( $\mathrm{NIH})$ /National Heart, Lung, and Blood Institute (NHLBI) to perform the present analysis under the coordination of the Biologic Specimen and Data Repository Information Coordinating Center (BioLINCC; request \#7509).

To be enrolled in the SPRINT trial, participants were required to meet all the following criteria: an age of at least 50 years, a systolic blood pressure, SBP of 130 to 180 $\mathrm{mm} \mathrm{Hg}$, and an increased risk of cardiovascular events (defined by one or more of the following: clinical or subclinical cardiovascular disease other than stroke; chronic kidney disease with an estimated glomerular filtration rate [eGFR] of 20 to $60 \mathrm{ml} / \mathrm{min} / 1.73 \mathrm{~m}^{2}$ calculated with the use of the four-variable Modification of Diet in Renal Disease Equation ${ }^{9}$; a 10 -year risk of cardiovascular disease $\geq 15 \%$ on the basis of the Framingham risk score; or an age $\geq 75$ years). Patients with diabetes mellitus or prior stroke were excluded.

Participants and study personnel were aware of the study-group assignments, but outcome adjudicators were not. The protocol encouraged, but did not mandate, the use of drug classes with the strongest evidence for reduction in cardiovascular outcomes ${ }^{10}$. Blood pressure was considered as the mean of three BP measurements at an office visit while the patient was seated after 5 minutes of quiet rest; the measurements were made with the use 
of an automated measurement system (Model 907, Omron Healthcare). The preferred method was the automated device as it offers reduced potential for observer biases and decreased demand on staff in terms of training and effort in data collection. Medical records and electrocardiograms were obtained for documentation of events. Whenever clinical site staff became aware of a death, a standard protocol was used to obtain information on the event. A total of 9361 participants were randomized. The trial was stopped earlier than expected after analyses of the primary outcome exceeded the monitoring boundaries at two consecutive time-points. The median follow-up time was 3.26 years. The primary outcome was a composite of myocardial infarction (MI), other acute coronary syndromes (ACS), stroke, heart failure (HF), or cardiovascular death. Compared with a standard systolic blood pressure target of $<140 \mathrm{mmHg}$ and intensive strategy with a $<120 \mathrm{mmHg}$, reduced the primary outcome $(6.8 \%$ vs $5.2 \%$; $1.65 \%$ per year vs. $2.19 \%$ per year; hazard ratio [HR] with intensive treatment, $0.75 ; 95 \%$ confidence interval $[\mathrm{Cl}], 0.64$ to $0.89 ; \mathrm{p}<0.001)^{7}$.

\section{Sexual health questionnaires}

Sexual health questionnaires were obtained in a subset of the SPRINT trial population ( $n=1881 ; 20 \%$ of the overall trial population), where 1268 were men and 613 women. The characteristics of these patients were similar to those of the overall trial population.

Supplemental Table 1. Throughout the trial, the most frequently prescribed anti-HT drugs were ACEi/ARBs and thiazides, followed by calcium-channel blockers and beta-blockers.

\section{Supplemental Table 2.}

For those engaged in sexual activities of any kind and who agreed to reply to the questionnaires (178 women and 862 men), the sexual health questions included an overall sexual life satisfaction question for both sexes, ranging from 1 (very dissatisfied) to 5 (very satisfied). Sexual health questionnaire for women was performed using a modified version 
of the Female Sexual Function Inventory $(\mathrm{FSFI})^{11}$, and included questions about their sexual desire or interest, sexual arousal, vaginal lubrication during sexual activity, orgasm frequency, satisfaction with sexual relationship and emotional closeness with partner. These questions were classified from 1 (almost never satisfied or very dissatisfied) to 5 (almost always or very satisfied). We have also dichotomized these variables in half of the times or more ( $\geq 3$ points) and less than half of the times ( $<3$ points).

For men the questionnaires were performed using the 5-item version of International Index of Erectile Function (IIEF-5) questionnaire ${ }^{12}$, and included questions about confidence to get and keep an erection, if the erections were hard enough for penetration, and whether the erections could be maintained after penetration. These questions were also classified from 1 (almost never or very dissatisfied) to 5 (almost always or very satisfied) and we have also dichotomized these variables in half of the times or more ( $\geq 3$ points) and less than half of the times ( $<3$ points).

These questionnaires are detailed in the Supplemental Material.

\section{Statistical analysis}

In descriptive analyses, continuous variables are expressed as mean \pm standard deviation (SD) or median (percentile $25-75$ ) based on their histogram distribution. Categorical variables are expressed as frequencies and proportions (\%). Population description and comparison of men vs. women was performed using independent samples t-test for normally distributed continuous variables, Mann-Whitney test for skewed variables, and chi-square test for categorical variables. As the aim of our study was to assess the impact on anti-HT therapy on the sexual function of men and women throughout the follow-up, the evolution of the sexual scores over time, was performed using linear (for continuous) and logistic (for binary) random-effects models for panel data i.e., data with multiple observations per patient over 
time (study visits: $0,6,12,24,36$, and 48 months). The sexual scores were set as dependent variables and visit time as independent variable. To assess the effect of treatment (intensive vs. standard) a treatment-by-time interaction was included in the model. The individual antiHT drugs used during the follow-up were retrieved from "free text" forms. To assess the impact of comorbidities on the sexual function scores, age, race, systolic blood pressure, body mass index, smoking history, number of anti-hypertensive agents, estimated glomerular filtration rate, presence of clinical or subclinical cardiovascular disease, total cholesterol levels, glucose levels, and urinary albumin-to-creatinine ratio were added to the panel data models in a multivariable fashion, retaining only the variables significantly associated with each individual sexual score in a stepwise backward fashion. Time-updated Cox models were used to study the association of erectile function and the study primary outcome adjusted on age, body mass index, chronic kidney disease and history of clinical or subclinical cardiovascular disease. All analyses were performed with the Stata ${ }^{\circledR}$ software (StataCorp. 2019. Stata Statistical Software: Release 16. College Station, TX: StataCorp LLC).

\section{Results}

\section{Baseline patients`characteristics by sex}

Among the 1268 men and 613 women included in this substudy, 862 (68\%) men and 178 (29\%) women declared to be engaged in sexual activity of any kind. Compared with women declaring not to be engaged in sexual activity of any kind, those who declared to be engaged in sexual activity were younger (64 vs. 69yr), more often current smokers, and with better renal function. Table 1. Compared with men not engaged in sexual activity of any kind, those who declared to be engaged in sexual activity were younger (65 vs. $71 \mathrm{yr}$ ), more often black, with slightly higher body mass index, and with better renal function. Table 1. 
Comparing men and women with sexual activity of any kind, women were slightly younger, more often black, more often current smokers, with higher HDL-cholesterol and less likely to be on a statin. Table 1.

\section{Baseline sexual health}

The main description of the questionnaires by sex is depicted in the Table 2. Women declared having an overall low satisfaction with their sexual life. Less than $50 \%$ of women declared to feel sexual desire or interest on at least half of the occasions and $30 \%$ said that they would almost never/never feel sexual desire; however, most declared to feel sexual arousal, become lubricated, and reach orgasm in at least half of the occasions they had sexual intercourse, most women were also satisfied with their relationship and emotional closeness during sexual activity. Table 2.

Most men said they felt at least moderately confident that they could get and keep an erection that the erections would be hard for penetration and maintained after penetration in most occasions. Table 2.

\section{Sexual health over time by sex and treatment allocation}

Women's sexual satisfaction, desire, arousal, lubrication, orgasm, and emotional closeness did not significantly change over time, neither did they differ by treatment allocation (i.e., they were not aggravated by intensive therapy). Table 3 \& Figure 1.

Men`s overall sexual satisfaction was maintained over time and did not differ by treatment group. However, they declared that their erections (particularly hard erections and their maintenance during intercourse) were slightly deteriorated over time $(-0.1$ to -0.2 points; $p<0.05)$, but they were not aggravated by intensive anti-HT therapy ( $p>0.05$ for all). Table 4 \& Figure 2. All therapeutic regimens could have had a negative impact on the 
quality of the erections, but those without thiazides and/or beta blockers could have been less impactful. Supplemental Table 3.

\section{Association with clinical features and comorbid conditions}

In men, older age (>65yr) and a body mass index above $30 \mathrm{Kg} / \mathrm{m}^{2}$, were associated with lower overall sexual satisfaction and lower quality of erections. Patients with clinical or subclinical cardiovascular disease and those with impaired renal function had more difficulty in maintaining erections. Supplemental Table 4. Women taking a higher number of anti-HT drugs were less satisfied with their sexual life, and older women (>65yr) had less sexual desire and became less often lubricated during sexual activity. Supplemental Table 4.

\section{Outcome associations}

Among men, 117 primary outcome events occurred. In adjusted models, the sexual/erectile function was not significantly associated with the study primary outcome. Supplemental Table 5. Among women, 31 primary outcome events occurred. Feeling sexual desire or interest more often was independently associated with a lower rate of the study primary outcome $(\mathrm{HR}[95 \% \mathrm{Cl}]=0.62[0.41-0.94], \mathrm{p}=0.025)$, but the other sex-related questions were not. Supplemental Table 5.

\section{Discussion}

This study shows that in a population with arterial hypertension and a moderate-to-high cardiovascular risk (but without diabetes or prior stroke), most women declared that they were not engaged in any sexual activity while most men declared they were. Women`s sexual desire was low but once they were engaged in sexual activities their sexual satisfaction was at least moderate in most occasions and was not deteriorated with intensive anti-HT therapy over time. Most men were confident that they could get and keep 
an erection, but the maintenance of hard erections was slightly diminished throughout the trial, albeit not aggravated by intensive therapy, suggesting that anti-HT treatment may impair the quality of erections but that is not dependent on the intensity of the anti-HT treatment.

Sexual dysfunction might be more prevalent in women than in men and is associated with poor physical and emotional health as well as poor overall well-being ${ }^{13}$. Although the sexual problems tend to increase with age, these seem to affect men in particular, still lubrication problems may also be aggravated with women`s age ${ }^{14}$. This study included mostly elderly people (mean age 67yr for women and 68yr for men) with moderate-high cardiovascular risk and hypertension, which is a population with a particularly high-risk for experiencing sexual dysfunction ${ }^{14}$. While most women declared that they were not engaged in any sexual activity, most men declared they were. The lack of sexual interest in older women has been reported, while most men could have stated to have more sexual interest due to fear of judgements about their "masculinity"14,15. Interestingly, women that stated to have a sexual activity of any kind reported to have an overall (at least) moderate sexual satisfaction. In a report using the baseline data of SPRINT, blood pressure was not associated with sexual activity in women, which was more related to psychosocial factors $^{16}$, and, at baseline, no single class of anti-HT medication was associated with sexual dysfunction in women ${ }^{17}$. Furthermore, our study shows that women did not experience any deterioration of their sexual health during the follow-up nor their sexual health was influenced by the allocation to an intensive anti-HT therapy regimen. These findings have clinical relevance, because they suggest that regardless of the baseline sexual health in women (that may be related to many other factors rather than blood pressure) 
this is unlikely to be deteriorated with an intensive treatment and should not preclude clinicians to try a systolic blood pressure goal of $120 \mathrm{mmHg}$.

Men were overall confident of their sexual performance, but many reported to have erectile problems at baseline and to have difficulties in maintaining an erection during sexual intercourse. These findings are compatible with other reports, stating that erectile dysfunction is common in men in their 60s and even more in men aged 70 and older, affecting more than $50 \%$ of men in these age ranges ${ }^{18,19}$. In patients with hypertension, erectile dysfunction has been independently associated with adverse cardiovascular outcomes ${ }^{20}$. In our report, the associations between erectile dysfunction and the study primary outcome did not reach statistical significance; probably due to the small size and few events in this subsample. In a report from SPRINT, baseline blood pressure was not associated with sexual activity in men either ${ }^{21}$. Our study suggests that erectile function (hard and sustained erections, in particular) may be aggravated with anti-hypertensive treatment over time; however, erectile dysfunction was not furtherly deteriorated with intensive anti-HF treatment for a SBP goal of $120 \mathrm{mmHg}$, which suggests that erectile dysfunction is not dependent on the intensity of the anti-HT therapy. In a report from SPRINT, the erectile dysfunction induced by a more intensive BP lowering strategy was found to be more marked in non-Hispanic blacks compared with non-Hispanic whites, differences that disappeared in the adjusted models ${ }^{22}$. In our report, race was not independently associated with any sexual/erection question in the fully adjusted models. In SPRINT (overall and in this subpopulation) the most commonly used anti-HT drug was angiotensin converting enzyme inhibitors/angiotensin receptor blockers (ACEi/ARBs) (in over $70 \%$ of the participant-episodes), followed by thiazide-type diuretics (over $50 \%$ ), calcium channel blockers (CCBs) (in almost 50\%), and beta-blockers (up to $40 \%$ ). The 
combination of ACEi/ARBs plus thiazides was used in $53 \%$ of the observations in men. Other anti-HT agents such as mineralocorticoid receptor antagonists (MRAs) and central acting drugs, were used in a much lower frequency $(<10 \%)$. The use of ACEi/ARBs and CCBs has been reported as not being associated with erectile dysfunction, with many reports showing a "neutral" effect of these agents in erectile function ${ }^{23-25}$; ARBs in particular by blocking the vasoconstrictive action of angiotensin II may positively affect erectile function and are thus regarded as a first-line treatment in hypertensive patients with erectile dysfunction ${ }^{26-29}$. On the other hand, thiazides, beta-blockers (with the possible exception of nebivolol) ${ }^{30}$, MRAs, and central-acting anti-HT agents may impair erectile function ${ }^{31-35}$. Unfortunately, for an adequate BP control one often requires anti-HT drug combinations, which often include a diuretic to increase sodium excretion ${ }^{36}$. In SPRINT this was no exception with more than half of men having a thiazide diuretic prescribed in association with other drugs, most frequently an ACEi/ARB. Nonetheless, consistently with prior studies, our observational data suggest that anti-HT regimens without beta-blockers or thiazides may be less impactful on erectile function.

\section{Limitations}

The impact of each individual drug on erectile function is hard to ascertain, because most patients take several medications that change over time and the individual effects of each drug cannot be assessed in a reliable fashion. However, the observation that an intensive anti-HT therapy does not furtherly deteriorate erectile function is reassuring and may help clinicians guiding their treatment strategies i.e., intensifying anti-HT treatment can improve outcomes and does not seem to further impact erectile function. The use of other medications (e.g., over the counter phospodoiestarase- 5 inhibitors) could not be accounted for because was not systematically recorded in the dataset; however, it is expected that the 
use of other (non anti-HT) medications that could impact sexual function was used similarly (i.e., at random) between the intensive and standard anti-HT therapy groups, and therefore does not impact our findings comparing the effect of intensive vs. standard anti-HT therapy on sexual function. The small number of events in this sexual questionnaire subsample (furtherly subdivided in men and women) likely lacked enough power to study the associations between sexual function and outcomes in a more robust fashion.

\section{Conclusion}

In SPRINT, women`s sexual health was maintained over time and was not affected by intensive anti-HT therapy. Men, declared having a slight deterioration in the quality of their erections over time, without further aggravation by intensive anti-HT therapy. These findings may help reassuring patients about the sexual safety of intensive anti-HT therapy, therefore, potentially improving adherence to intensive therapy strategy.

\section{Clinical perspectives}

Women had an overall low satisfaction with their sexual life but their sexual health was not affected by anti-hypertensive therapy over time nor modified by an intensive treatment. Men's erections were slightly deteriorated over time but were not aggravated by an intensive anti-hypertensive therapy.

These findings may help reassuring patients about the sexual safety of intensive antihypertensive therapy and improve treatment adherence.

\section{Acknowledgments}


The authors would like to acknowledge the National Institutes of Health (NIH) for providing

the SPRINT trial dataset.

\section{Disclosures}

The content of this manuscript is solely the responsibility of the authors and does not necessarily represent the official views of the National Institutes of Health (NIH), the Department of Veterans Affairs, or the U.S. Government.

\section{Bibliography}

1. Kearney, P. M.; Whelton, M.; Reynolds, K.; Muntner, P.; Whelton, P. K.; He, J., Global burden of hypertension: analysis of worldwide data. Lancet 2005, 365 (9455), 217-23.

2. Burnier, M., Medication adherence and persistence as the cornerstone of effective antihypertensive therapy. Am J Hypertens 2006, 19 (11), 1190-6.

3. Durand, H.; Hayes, P.; Morrissey, E. C.; Newell, J.; Casey, M.; Murphy, A. W.; Molloy, G. J., Medication adherence among patients with apparent treatment-resistant hypertension: systematic review and meta-analysis. J Hypertens 2017, 35 (12), 2346-2357.

4. Prisant, L. M.; Carr, A. A.; Bottini, P. B.; Solursh, D. S.; Solursh, L. P., Sexual dysfunction with antihypertensive drugs. Arch Intern Med 1994, 154 (7), 730-6.

5. Viigimaa, M.; Vlachopoulos, C.; Lazaridis, A.; Doumas, M., Management of erectile dysfunction in hypertension: Tips and tricks. World J Cardiol 2014, 6 (9), 908-15.

6. Hershfield, H. E., Future self-continuity: how conceptions of the future self transform intertemporal choice. Ann N Y Acad Sci 2011, 1235, 30-43.

7. Wright, J. T., Jr.; Williamson, J. D.; Whelton, P. K.; Snyder, J. K.; Sink, K. M.; Rocco, M. V.; Reboussin, D. M.; Rahman, M.; Oparil, S.; Lewis, C. E.; Kimmel, P. L.; Johnson, K. C.; Goff, D. C., Jr.; Fine, L. J.; Cutler, J. A.; Cushman, W. C.; Cheung, A. K.; Ambrosius, W. T., A Randomized Trial of Intensive versus Standard Blood-Pressure Control. N Engl J Med 2015, 373 (22), 2103-16.

8. Ambrosius, W. T.; Sink, K. M.; Foy, C. G.; Berlowitz, D. R.; Cheung, A. K.; Cushman, W. C.; Fine, L. J.; Goff, D. C., Jr.; Johnson, K. C.; Killeen, A. A.; Lewis, C. E.; Oparil, S.; Reboussin, D. M.; Rocco, M. V.; Snyder, J. K.; Williamson, J. D.; Wright, J. T., Jr.; Whelton, P. K., The design and rationale of a multicenter clinical trial comparing two strategies for control of systolic blood pressure: the Systolic Blood Pressure Intervention Trial (SPRINT). Clin Trials 2014, 11 (5), 532-46. 9. Levey, A. S.; Bosch, J. P.; Lewis, J. B.; Greene, T.; Rogers, N.; Roth, D., A more accurate method to estimate glomerular filtration rate from serum creatinine: a new prediction equation. Modification of Diet in Renal Disease Study Group. In Ann Intern Med, United States, 1999; Vol. 130, pp 461-70.

10. Chobanian, A. V.; Bakris, G. L.; Black, H. R.; Cushman, W. C.; Green, L. A.; Izzo, J. L., Jr.; Jones, D. W.; Materson, B. J.; Oparil, S.; Wright, J. T., Jr.; Roccella, E. J., The Seventh Report of the Joint National Committee on Prevention, Detection, Evaluation, and Treatment of High Blood Pressure: the JNC 7 report. Jama 2003, 289 (19), 2560-72. 
11. Rosen, R.; Brown, C.; Heiman, J.; Leiblum, S.; Meston, C.; Shabsigh, R.; Ferguson, D.; D'Agostino, R., Jr., The Female Sexual Function Index (FSFI): a multidimensional self-report instrument for the assessment of female sexual function. J Sex Marital Ther 2000, 26 (2), 191-208. 12. Rosen, R. C.; Cappelleri, J. C.; Smith, M. D.; Lipsky, J.; Pena, B. M., Development and evaluation of an abridged, 5 -item version of the International Index of Erectile Function (IIEF-5) as a diagnostic tool for erectile dysfunction. Int J Impot Res 1999, 11 (6), 319-26.

13. Laumann, E. O.; Paik, A.; Rosen, R. C., Sexual dysfunction in the United States: prevalence and predictors. Jama 1999, 281 (6), 537-44.

14. Laumann, E. O.; Nicolosi, A.; Glasser, D. B.; Paik, A.; Gingell, C.; Moreira, E.; Wang, T., Sexual problems among women and men aged $40-80 \mathrm{y}$ : prevalence and correlates identified in the Global Study of Sexual Attitudes and Behaviors. Int J Impot Res 2005, 17 (1), 39-57.

15. Moreira, E. D., Jr.; Kim, S. C.; Glasser, D.; Gingell, C., Sexual activity, prevalence of sexual problems, and associated help-seeking patterns in men and women aged 40-80 years in Korea: data from the Global Study of Sexual Attitudes and Behaviors (GSSAB). J Sex Med 2006, 3 (2), 201-11.

16. Foy, C. G.; Newman, J. C.; Berlowitz, D. R.; Russell, L. P.; Kimmel, P. L.; Wadley, V. G.; Thomas, H. N.; Lerner, A. J.; Riley, W. T., Blood Pressure, Sexual Activity, and Dysfunction in Women With Hypertension: Baseline Findings From the Systolic Blood Pressure Intervention Trial (SPRINT). J Sex Med 2016, 13 (9), 1333-1346.

17. Thomas, H. N.; Evans, G. W.; Berlowitz, D. R.; Chertow, G. M.; Conroy, M. B.; Foy, C. G.; Glasser, S. P.; Lewis, C. E.; Riley, W. T.; Russell, L.; Williams, O.; Hess, R., Antihypertensive medications and sexual function in women: baseline data from the SBP intervention trial (SPRINT). $J$ Hypertens 2016, 34 (6), 1224-31.

18. Selvin, E.; Burnett, A. L.; Platz, E. A., Prevalence and risk factors for erectile dysfunction in the US. Am J Med 2007, 120 (2), 151-7.

19. Ayta, I. A.; McKinlay, J. B.; Krane, R. J., The likely worldwide increase in erectile dysfunction between 1995 and 2025 and some possible policy consequences. BJU Int 1999, 84 (1), 50-6.

20. Bohm, M.; Baumhakel, M.; Teo, K.; Sleight, P.; Probstfield, J.; Gao, P.; Mann, J. F.; Diaz, R.; Dagenais, G. R.; Jennings, G. L.; Liu, L.; Jansky, P.; Yusuf, S., Erectile dysfunction predicts cardiovascular events in high-risk patients receiving telmisartan, ramipril, or both: The ONgoing Telmisartan Alone and in combination with Ramipril Global Endpoint Trial/Telmisartan Randomized AssessmeNt Study in ACE iNtolerant subjects with cardiovascular Disease (ONTARGET/TRANSCEND) Trials. Circulation 2010, 121 (12), 1439-46.

21. Foy, C. G.; Newman, J. C.; Berlowitz, D. R.; Russell, L. P.; Kimmel, P. L.; Wadley, V. G.; Thomas, H. N.; Lerner, A. J.; Riley, W. T., Blood Pressure, Sexual Activity, and Erectile Function in Hypertensive Men: Baseline Findings from the Systolic Blood Pressure Intervention Trial (SPRINT). J Sex Med 2019, 16 (2), 235-247.

22. Foy, C. G.; Newman, J. C.; Russell, G. B.; Berlowitz, D. R.; Bates, J. T.; Burgner, A. M.; Carson, T. Y.; Chertow, G. M.; Doumas, M. N.; Hughes, R. Y.; Kostis, J. B.; Buren, P. V.; Wadley, V. G., Effect of Intensive vs Standard Blood Pressure Treatment Upon Erectile Function in Hypertensive Men: Findings From the Systolic Blood Pressure Intervention Trial. J Sex Med 2020, 17 (2), 238-248.

23. Suzuki, H.; Tominaga, T.; Kumagai, H.; Saruta, T., Effects of first-line antihypertensive agents on sexual function and sex hormones. J Hypertens Supp/ 1988, 6 (4), S649-51.

24. Omvik, P.; Thaulow, E.; Herland, O. B.; Eide, I.; Midha, R.; Turner, R. R., Double-blind, parallel, comparative study on quality of life during treatment with amlodipine or enalapril in mild or moderate hypertensive patients: a multicentre study. J Hypertens 1993, 11 (1), 103-13.

25. Kroner, B. A.; Mulligan, T.; Briggs, G. C., Effect of frequently prescribed cardiovascular medications on sexual function: a pilot study. Ann Pharmacother 1993, 27 (11), 1329-32.

26. Llisterri, J. L.; Lozano Vidal, J. V.; Aznar Vicente, J.; Argaya Roca, M.; Pol Bravo, C.; Sanchez Zamorano, M. A.; Ferrario, C. M., Sexual dysfunction in hypertensive patients treated with losartan. Am J Med Sci 2001, 321 (5), 336-41. 
27. Dusing, R., Effect of the angiotensin II antagonist valsartan on sexual function in hypertensive men. Blood Press Supp/ 2003, 2, 29-34.

28. Della Chiesa, A.; Pfiffner, D.; Meier, B.; Hess, O. M., Sexual activity in hypertensive men. J Hum Hypertens 2003, 17 (8), 515-21.

29. Baumhakel, M.; Custodis, F.; Schlimmer, N.; Laufs, U.; Bohm, M., Improvement of endothelial function of the corpus cavernosum in apolipoprotein $E$ knockout mice treated with irbesartan. J Pharmacol Exp Ther 2008, 327 (3), 692-8.

30. Baumhakel, M.; Schlimmer, N.; Buyukafsar, K.; Arikan, O.; Bohm, M., Nebivolol, but not metoprolol, improves endothelial function of the corpus cavernosum in apolipoprotein e-knockout mice. J Pharmacol Exp Ther 2008, 325 (3), 818-23.

31. Fogari, R.; Zoppi, A.; Poletti, L.; Marasi, G.; Mugellini, A.; Corradi, L., Sexual activity in hypertensive men treated with valsartan or carvedilol: a crossover study. Am J Hypertens 2001, 14 (1), 27-31.

32. Brixius, K.; Middeke, M.; Lichtenthal, A.; Jahn, E.; Schwinger, R. H., Nitric oxide, erectile dysfunction and beta-blocker treatment (MR NOED study): benefit of nebivolol versus metoprolol in hypertensive men. Clin Exp Pharmacol Physiol 2007, 34 (4), 327-31.

33. Williams, G. H.; Croog, S. H.; Levine, S.; Testa, M. A.; Sudilovsky, A., Impact of antihypertensive therapy on quality of life: effect of hydrochlorothiazide. J Hypertens Supp/ 1987, 5 (1), S29-35.

34. Grimm, R. H., Jr.; Grandits, G. A.; Prineas, R. J.; McDonald, R. H.; Lewis, C. E.; Flack, J. M.; Yunis, C.; Svendsen, K.; Liebson, P. R.; Elmer, P. J., Long-term effects on sexual function of five antihypertensive drugs and nutritional hygienic treatment in hypertensive men and women.

Treatment of Mild Hypertension Study (TOMHS). Hypertension 1997, 29 (1 Pt 1), 8-14.

35. Baumhakel, M.; Schlimmer, N.; Kratz, M.; Hackett, G.; Jackson, G.; Bohm, M., Cardiovascular risk, drugs and erectile function--a systematic analysis. Int J Clin Pract 2011, 65 (3), 289-98.

36. Burnier, M.; Bakris, G.; Williams, B., Redefining diuretics use in hypertension: why select a thiazide-like diuretic? J Hypertens 2019, 37 (8), 1574-1586. 
Figure 1. Women: change in lubrication and satisfaction during sexual intercourse over time and by treatment (intensive vs. standard)

A) Change over time

B) Change by treatment

Legend: No significant differences observed (all $p>0.05$ ). 
Figure 2. Men: change in the quality of erections during sexual intercourse over time and by treatment (intensive vs. standard)

A) Change over time

B) Change with treatment

Caption: Slight decrease in the quality of erections over time ( $p<0.05$ for all time-points, except 48 months were the estimates are imprecise due to low number of patients) but not by intensive treatment (vs. standard) ( $p>0.05$ for all comparisons). 